\title{
Historia del paramilitarismo en Colombia
}

Edgar de Jesús Velásquez Rivera*

Resumen: En Colombia, desde la década de los años ochenta del siglo XX tomó fuerza el paramilitarismo como estrategia contrainsurgente, política que no ha sido reconocida como tal por parte de los distintos gobiernos y se expresa como terrorismo de Estado. Incidió en el surgimiento de tal fenómeno, la ideología anticomunista que profesan la mayoría de miembros de las fuerzas armadas, la cultura política derivada de la violencia, la corrupción y el clientelismo, así como el narcotráfico, al igual que las influencias externas, provenientes principalmente de Francia y Estados Unidos. El paramilitarismo invadió las distintas estructuras del poder estatal, en la perspectiva de configurarse como un proyecto político, militar, social y económico de alcance nacional. Originado, según sus mentores, como una respuesta a los excesos de la guerrilla, el paramilitarismo ha privilegiado, como método de lucha, las masacres, asesinatos selectivos y desplazamientos de población civil, acusados de ser simpatizantes o colaboradores de las guerrillas. Al presidente Álvaro Uribe Vélez, se le atribuye el haber auspiciado el paramilitarismo y de institucionalizarlo en su gestión de gobierno.

Palabras clave: paramilitares, poder, violencia, gobierno.

\section{Introducción}

Contrario a lo que comúnmente se cree, dicho fenómeno no es reciente, ha sido una práctica política a la cual han recurrido las elites políticas, económicas y de la mafia para conseguir el poder, expandirlo y afianzarse en él. Si bien es cierto hubo un ambiente interno propicio para su aparición y auge, el paramilitarismo no puede ser visto al margen de la incidencia geopolítica de Estados Unidos que, en materia de estrategia contrainsurgente, se le inculcó a los militares formados en sus escuelas, país que a su vez fue influenciado por Francia. El paramilitarismo es uno de los principales factores incidentes en la violencia y en la degradación de la misma. Se calcula que una parte de sus víctimas, aquellas arrojadas en fosas comunes, en número superan con creces a las registradas en los países del cono sur donde hubo dictaduras militares.

Los gobiernos de dicho país no han tenido voluntad para enfrentar y erradicar el paramilitarismo, por el contrario, a través de miembros de las fuerzas armadas lo han apoyado, al creerlos aliados en su lucha contra la subversión. Este artículo pretende ofrecer una aproximación histórica sobre el paramilitarismo en Colombia, para tal 
efecto, alude a las influencias, su auge, los mecanismos por los cuales se expandió, las distintas formas como se ha reaccionado frente a los hechos y, finalmente, se ofrecen algunas reflexiones finales.

\section{Lo heredado}

Los franceses, en el contexto de la política colonialista y de represión a los movimientos independentistas de sus colonias de Indochina y Argelia, crearon organizaciones paramilitares o escuadrones de la muerte como estrategia contrainsurgente. ${ }^{1}$ En ambos casos aplicaron las torturas y practicaron las desapariciones. Según los militares franceses, era preferible eliminar a un inocente que dejar libre a un subversivo. Concluyeron que quien controlara y ganara la población tenía el éxito asegurado, y ante las dificultades para su adhesión, dedujeron que el desplazamiento de la población civil era una forma de quitarle el apoyo al enemigo y por eso forzaron los desplazamientos. Para los mismos, “... todo sospechoso es un muerto con la ejecución aplazada ...”. 2

Este conjunto de ideas incidió en los fundamentos ideológicos de la doctrina de la seguridad nacional, matriz del paramilitarismo en América Latina, a través de los militares franceses Charles Lacheroy, Marcel Bigeard, Jacques Massu, Paul Aussaresses, Paul-Alzin Léger, André Beaufré y Roger Trinquier quien justificó la tortura. ${ }^{3}$ Para este último personaje "Los interrogatorios deben llevarse a cabo por especialistas que estén bien informados sobre la técnica que se emplea”. 4 Según dicho militar, "El control de las masas a través de organizaciones es un arma básica contra la insurgencia. Si la población no coopera hay que buscar dicha cooperación por medio del peligro". ${ }^{5}$ El paramilitarismo ${ }^{6}$ hizo parte del catálogo de enseñanzas ofrecidas por Trinquier al ejército estadounidense, el cual a su vez las replicó en las fuerzas armadas latinoamericanas.

La Batalla de Argel llegó a ser un modelo de la guerra contrarrevolucionaria a partir de los escuadrones de la muerte. ${ }^{7}$ Desde mayo de 1958 las técnicas de la Batalla de Argel comenzaron a enseñarse, primero desde 1958 en la Escuela de Guerra de París, donde los primeros alumnos fueron $\operatorname{argentinos}^{8} \mathrm{y}$, posteriormente, en la Escuela Superior de Guerra de Buenos Aires desde 1961, donde participaron militares de 14 países, inclusive de Estados Unidos, en calidad de estudiantes. ${ }^{9}$ Posteriormente los franceses capacitaron a los militares estadounidenses a través de Pierre Messmer y Paul Aussaresses quien fue nombrado en la agregaduría militar en Washington, de la que 
dependían diez oficiales de enlace, todos veteranos de Argelia y fueron distribuidos en distintas escuelas militares estadounidenses. ${ }^{10}$ Los militares estadounidenses diseminaron lo aprendido a los franceses a través de la Escuela de las Américas, ${ }^{11}$ entre ello, la formación de organizaciones paramilitares. ${ }^{12}$ Se calcula que en la Escuela de las Américas (US Army Scholl of the Américas. USARSA), ${ }^{13}$ sin ser la única dedicada a tales propósitos, 100.000 militares latinoamericanos fueron formados allí, entre ellos, 4.629 colombianos, solamente entre 1950-1970. Pero antes de esta influencia francesa, Estados Unidos ya había implementado los escuadrones de la muerte o paramilitares en países de América Latina.

Dicho fenómeno se presentó en la mayoría de países de la región del siguiente modo: en la República Dominicana, los Cocuyos de la Cordillera, Legión Extranjera y Jinetes del Este los cuales apoyaron a Rafael Leonidas Trujillo para que tomara en poder en $1930 \mathrm{y}$, en el contexto de la guerra fría, fue creado otro escuadrón de la muerte denominado La Banda; en Nicaragua, los Camisas Azules, quienes junto a Estados Unidos promovieron a Anastasio Somoza García al poder en 1936; en Guatemala, las Patrullas de Autodefensa Civil (PAC), la Mano Blanca y Ojo por Ojo; en Honduras, el Batallón 316; en El Salvador, hubo más de doce organizaciones paramilitares, una de ellas llamada Fuerzas Armadas de Liberación Anticomunista-Guerra de Eliminación (FALANGE); en México, los Cuerpos de Defensas Rurales de la Secretaría de la Defensa Nacional (SEDENA); en Nicaragua, la Fuerza Democrática nicaragüense y la Alianza Revolucionaria Democrática, conocidas como La Contra; en Perú, el Comando Rodrigo Franco y Colina; en Costa Rica, la guardia civil; en Panamá, se infiltran los paramilitares en las marchas y asesinan a dirigentes; Argentina, la Alianza Anticomunista Argentina (Triple A) y en Chile, Patria y Libertad.

También hubo escuadrones de la muerte en Brasil, Paraguay, Bolivia, Ecuador y Venezuela. El rasgo común de los escuadrones de la muerte o paramilitares, fue el haber sido creados por parte de las fuerzas regulares de cada país, con la asesoría de CIA. Según Ralph W. McGehee, quien formó parte de la CIA entre 1952 y 1977, dicha institución organizó escuadrones de la muerte en El Salvador, Guatemala, Nicaragua (antes de 1979), Corea del Sur, Irán, Chile y Uruguay. Este mismo personaje asevera que, en 1969, fue enviado a Uruguay el agente de la CIA, experto en torturas, Dan Mitrione para asesorar a las fuerzas armadas y a los escuadrones de la muerte de ese país. Mitrione solía decir: "El dolor exacto, en el lugar exacto, en la cantidad exacta para obtener el efecto deseado”. 


\title{
2. Lo propio
}

La estrategia del Estado colombiano de formar, entrenar, armar y utilizar organizaciones armadas al margen de la ley contra aquellos que considera sus enemigos no es reciente. Según Daniel García-Peña Jaramillo, las raíces del paramilitarismo

\begin{abstract}
se encuentran en la vieja práctica de las elites colombianas de utilizar la violencia para obtener y mantener sus propiedades y sus privilegios en connivencia con el Estado. Los antecedentes más cercanos se encuentran en los grupos que surgieron en la violencia de los años cuarenta y cincuenta ... (cuando) ... Grupos privados, como los denominados Pájaros, operaron con el apoyo y la complicidad de las autoridades. ${ }^{14}$
\end{abstract}

Tal fue el caso de la organización paramilitar La Chulavita, destinada a eliminar a los liberales.

En octubre de 1962 llegó a Colombia el general William Yarborough quien era comandante del Special Warfare Center de Fort Bragg en Carolina del Norte, el mismo que sirvió de cuartel general a la 82 División, más conocida como la de los Green Berets o Boinas Verdes, recordados por su participación en la guerra de Vietnam. La misión Yarborough recomendó crear organizaciones nuevas de tipo antiterrorista y grupos de lucha anticomunista al igual que la organización de grupos paramilitares secretos para llevar a cabo operaciones violentas contra la oposición. ${ }^{15}$

Así pues, en el contexto geopolítico de guerra fría y del Frente Nacional 19581974,

En los sesenta, ... se estableció el fundamento jurídico para la conformación de grupos de autodefensa bajo el auspicio y control de las fuerzas armadas, mediante el decreto legislativo 3398 de 1965, que fue convertido en legislación permanente por la ley 48 de $1968 .{ }^{16}$

Después se expidió la Resolución 005 por medio de la cual se aprobó el llamado "Reglamento de Combate de Contraguerrillas”. Para ese entonces se recomendó desde Estados Unidos “Si una guerra limitada convencional entraña demasiados riesgos, entonces las técnicas paramilitares pueden proveer una manera segura y útil que permita aplicar la fuerza a fin de lograr los fines políticos”. ${ }^{17}$

El paramilitarismo como estrategia contrainsurgente en Colombia ha sido una política de Estado, no ha sido un hecho aislado o coyuntural, ha correspondido a una ideología de terrorismo de Estado con sus naturales variaciones dependiendo de las circunstancias de cada momento. En los años ochenta, en el contexto de la política de 
paz impulsada por el presidente Belisario Betancur Cuartas (1982-1986), los militares, la derecha y los narcotraficantes consideraron que el Estado había otorgado ventajas inadmisibles a las organizaciones subversivas y desde su perspectiva ideológica e intereses se consideraron obligados a asumir la defensa del establecimiento y para ello impulsaron, crearon y financiaron grupos paramilitares como estrategia contrainsurgente, entre ellos: Muerte a Secuestradores (MAS), el Escuadrón de la Muerte, Muerte a Abigeos (MAOS), Castigo a Firmantes o Intermediarios Estafadores (CAFIES), el Embrión, Alfa 83, Prolimpieza del Valle del Magdalena, Tiznados, Movimiento Anticomunista Colombiano, los Grillos, el Escuadrón Machete, Falange, Muerte a Invasores, Colaboradores y Patrocinadores (MAICOPA), los Comandos Verdes, Terminador, Menudos, Justiciero Implacable, Mano Negra y Plan Fantasma, ${ }^{18}$ los Grises, Rambo, Toticol, los Criollos y Black Flag, ${ }^{19}$ entre los más conocidos.

En este ambiente fueron incrementadas las organizaciones paramilitares, como complemento a la lucha antisubversiva, hasta convertirse en la principal estrategia del Estado colombiano en ese sentido, cuando esas organizaciones, entre 1996 y 1997, se aglutinaron en torno a las Autodefensas Unidas de Colombia (AUC), comandadas por Carlos Castaño Gil. Un balance general del desarrollo del paramilitarimo de los años comprendidos entre 1979 y 1994, afirma Carlos Medina Gallego, refleja la persecución sistemática, el hostigamiento, la detención arbitraria, la práctica de la tortura y la realización de consejos verbales de guerra que caracterizaron la administración del presidente Julio César Turbay Ayala (1978-1982).

De ahí se pasó a la utilización de la amenaza, el asesinato selectivo y las masacres, durante la administración Betancur Cuartas. Luego se llegó a las prácticas de la violencia expresada en detención-desaparición, y masacres colectivas que caracterizaron las administraciones de Virgilio Barco Vargas (1986-1990) y César Gaviria Trujillo (1990-1994), ${ }^{20}$ según Medina Gallego. En la primera parte de los años ochenta las organizaciones paramilitares fueron la respuesta de los narcotraficantes contra el secuestro y la extorsión, luego evolucionaron hacia un proyecto político, militar y social con la colaboración y complacencia de las fuerzas armadas. ${ }^{21}$ Mauricio Romero, otro estudioso del tema, llegó a esta misma conclusión, según Vargas Velásquez. $^{22}$

Desde el punto de vista de Medina Gallego, para los mentores de las organizaciones paramilitares como política contrainsurgente, en Colombia se desarrollaba una guerra no convencional entre la democracia y el comunismo. El blanco 
en esta guerra no fueron, necesariamente los grupos insurgentes, sino la población civil concebida como la base social y política del enemigo. Desde esa perspectiva la guerra se libró en todos los ámbitos (político, social, económico, psicológico, militar). Los militares colombianos cambiaron de ese modo la estrategia contrainsurgente, delegaron en los paramilitares “el trabajo sucio” de eliminar a trabajadores, campesinos, maestros, políticos y líderes sindicales de izquierda, por ser, supuestamente, guerrilleros de civil que habían infiltrado las organizaciones sindicales, políticas, la iglesia, los gremios y las mismas instituciones estatales. En esta guerra no convencional se registraron los genocidios, las masacres, las detenciones-desapariciones, las eliminaciones selectivas, individuales y colectivas y la limpieza social (delincuentes comunes, drogadictos, homosexuales). ${ }^{23}$

En las administraciones posteriores a la Betancur Cuartas hubo un crecimiento exponencial del paramilitarismo. Durante la gestión de Barco Vargas fueron identificadas cerca de 200 organizaciones paramilitares. Durante esta misma administración, en 1988, el gobierno declaró ilegales a las autodefensas y estableció la tipificación de la conformación de éstas como conducta punible, mediante los decretos 813, 814 y $815 .{ }^{24}$ Por su parte, Gaviria Trujillo le declaró la "guerra integral” a la subversión, no al paramilitarismo.

El presidente Ernesto Samper Pizano (1994-1998), por medio de su ministro de defensa, Fernando Botero Zea, impulsó las Asociaciones Comunitarias de Vigilancia Rural, “Convivir”, como una forma de regularizar el paramilitarismo, las Convivir tuvieron su respaldo legal en los Decretos 2535 de 1993 y 356 de 1994 con la función de contribuir con labores de inteligencia para las fuerzas armadas $\mathrm{y}$, declaradas inexequibles en 1999, el Estado no recuperó las armas y sus miembros se emplearon a ganaderos y narcotraficantes. Las Convivir, tuvieron su principal epicentro en el Departamento de Antioquia, donde fungía como gobernador Álvaro Uribe Vélez.

Desde el punto de vista de García-Peña Jaramillo,

El gobierno de Andrés Pastrana (1998-2002) ... incluyó la lucha contra los grupos paramilitares como parte de su plan estratégico, ordenó el desmonte total de las Convivir, destituyó a los generales Rito Alejo del Río y Fernando Millán por sus nexos con paramilitares e incluyó el combate a los grupos de autodefensa como tema de la Agenda Común por el Cambio hacia una Nueva Colombia, firmada con las FARC en el Caguán. ${ }^{25}$ 
Dicha agenda marcó el inicio de los diálogos de paz, el 7 de enero de 1999, ante lo cual los paramilitares incrementaron las masacres y los sabotajes al proceso de paz con dicha guerrilla.

El presidente Álvaro Uribe Vélez (2002-2006 y 2006-2010) adoptó la Ley de Justicia y Paz o la legalización del paramilitarismo, en el sentido de asegurar la impunidad de sus acciones, permitirles legalizar sus bienes ilícitos y dotarlos de facilidades para el ejercicio político. Un rasgo peculiar a todas estas administraciones fue su pasividad frente al crecimiento del fenómeno paramilitar. El paramilitarismo rompió los cauces dentro de los cuales los mantuvo sus mentores e invadió los poderes ejecutivo, legislativo y judicial, el DAS (Policía secreta colombiana), instituciones financieras, alcaldías, gobernaciones e incluso algunas universidades, según lo señalaron congresistas opositores al gobierno de Uribe Vélez.

Se indican casos concretos que relacionan a los militares colombianos con paramilitares. Tal fue el caso de los grupos paramilitares del Magdalena Medio, organizados por el ex comandante militar de Puerto Boyacá, coronel Luis Bohórquez quien, ante la prensa hablada manifestó:

Las autodefensas no entregarán las armas, las devuelven al mismo Estado quien un día las reclutó, las organizó y las armó. Era una obligación para los comandantes poder erradicar la guerrilla y el comunismo de la zona. Actualmente hay 15.000 hombres en armas. ${ }^{26}$

En ocasiones los militares se presentaron en zonas rurales como paramilitares, con sus insignias y prendas distintivas y actuaron como tales.

El paramilitarismo como recurso para luchar contra la subversión es una política de Estado así no esté consagrada legalmente. "Se trata de una doctrina institucional aplicada sistemáticamente, que ha comprometido todas las instancias de la Fuerza Pública”27. Como muestra de lo anterior,

En su testimonio ante la justicia, el oficial del ejército y luego comandante paramilitar Luis Antonio Meneses declaró que hasta 1989 los contactos se hacían directamente entre el Estado Mayor del Ejército y la dirección de las autodefensas. Después se comenzaron a utilizar intermediarios. $^{28}$

De lo anterior se deduce que las relaciones entre las fuerzas armadas colombianas y las organizaciones paramilitares son orgánicas. Naturalmente ello no aparece en el organigrama de las primeras, ni en sus líneas de mando ni figuran como organismos institucionalizados, pero ello no es óbice para que de manera paralela, 
secreta o encubierta las relaciones funcionen con arreglo a fines. Las fuerzas armadas pasaron, de tener el control sobre los paramilitares, a ser controladas por éstos y, el cambio de la naturaleza de este tipo de relaciones explica, en parte, la facilidad con que además de expandirse, el paramilitarismo penetró la mayoría de las instituciones del Estado.

Tanto el estamento castrense como los distintos jefes de Estado, cuando se les cuestiona tal situación, la niegan rotundamente $\mathrm{y}$, cuando las pruebas son incontrovertibles, evaden sus responsabilidades afirmando que se trata de hechos aislados y que en modo alguno comprometen a las instituciones y menos aún que se trata de una política de Estado, ${ }^{29}$ como ocurrió con la separación del ejército, del coronel Hernán Mejía Gutiérrez, por sus nexos con paramilitares según denuncias a organismos de control del Estado por parte de un subalterno suyo. ${ }^{30}$

El paramilitarismo desembozado desde los años ochenta del siglo XX es una expresión del terrorismo de Estado. ${ }^{31}$ Quienes por diversos mecanismos estimularon el paramilitarismo, aducen que fue la consecuencia de "La ausencia del Estado, que permitió que la guerrilla pudiera copar territorios. Como consecuencia, ciudadanos que estaban indefensos en el campo se vieron obligados a organizarse para poder enfrentar la guerrilla”32. El líder paramilitar Rodrigo Tovar Pupo, alias Jorge 40, en su declaración a la Fiscalía en julio de 2006, afirmó:

Nosotros, como organización política y militar, reemplazamos al Estado en sus funciones, tanto en la ejecutiva como en la legislativa y judicial, pues nuestra lucha política nos llevó a eso, ya que nos tocó reestablecer las funciones que el Estado debía cumplir y nunca hizo. ${ }^{33}$

Esta tesis es compartida por la derecha colombiana.

Mientras se adelantaban los diálogos de paz entre el gobierno de Pastrana Arango y las FARC, en el municipio de San Vicente del Caguán, departamento del Caquetá, a los cuales se opuso tenazmente Uribe Vélez y las AUC; el 23 de julio de 2001, en Santa Fe de Ralito, Departamento de Córdoba, se firmó un documento entre los líderes de las AUC y un grupo de 32 políticos, la mayoría de ellos de filiación conservadora, cuyos postulados hablan de "refundar la patria” y "firmar un nuevo contrato social”. 34

Las alianzas entre la clase política colombiana y organizaciones criminales han sido una práctica recurrente, entre las más evidentes se pueden destacar tres. La primera, entre el Cartel de Medellín liderado por Pablo Escobar Gaviria y políticos liberales y 
conservadores. La segunda, entre el Cartel de Cali, liderado por los hermanos Rodríguez Orejuela y políticos de las mismas colectividades; y la tercera alianza ocurrió entre un sector de la clase política, diversos estamentos y paramilitares. ${ }^{35}$

\section{La expansión del paramilitarismo}

Rafael García, Jefe de Informática del DAS, en abril de 2006 denunció que esa organización estaba al servicio de los paramilitares. Desde noviembre de 2006, en Colombia empezó a hacerse, parcialmente público, el escándalo referido a las relaciones de políticos, empresarios, terratenientes, religiosos, industriales, comerciantes, comunicadores, organismos de seguridad del Estado y militares con las AUC, conocidas como paramilitares. Tal fenómeno se conoce como el escándalo de la parapolítica.

La expansión del paramilitarismo en Colombia tuvo varias vías. La adelantada por las propias instituciones y estamentos que lo crearon, la propiciada a raíz de la indiferencia de los distintos gobiernos nacionales frente a tal fenómeno, la liderada por gobernadores a través de organizaciones de apariencia legal como fueron las Convivir y la implementada por narcotraficantes consistente en formar grupos armados para su servicio los cuales fueron incorporados al paramilitarismo, incluso comprándole franquicias a éste para evadir de ese modo la acción de la justicia nacional e internacional.

Las autoridades civiles del orden ejecutivo como gobernadores y alcaldes, los organismos secretos de seguridad como el DAS y la SIJIN, personalidades políticas como concejales, diputados, representantes a la cámara y senadores, el poder judicial, la iglesia católica y los medios de comunicación, guardaron silencio. Las centrales obreras, los sindicatos, las organizaciones no gubernamentales, las universidades, los partidos de izquierda, las organizaciones campesinas y las mismas organizaciones guerrilleras no hicieron lo suficiente para oponerse al paramilitarismo.

Los primeros en denunciar en Colombia la expansión del paramilitarismo y el copamiento que éste hiciera de las distintas estructuras de poder e instituciones públicas fueron los partidos de izquierda y las organizaciones guerrilleras desde la década de los años ochenta. Sin embargo, seguramente por provenir de donde provenían las denuncias, casi nadie puso atención y, en las más de las veces, tales denuncias fueron catalogadas como simples “calumnias de la oposición”. 
Desde entonces, en el ámbito nacional surgieron personeros dedicados a legitimar, justificar y defender tanto el paramilitarismo, como las relaciones de las fuerzas armadas con éste, pasando por el narcotráfico y la ola de crímenes en nombre de una cruzada anticomunista. Tales defensores destacaron por su febril defensa del paramilitarismo en tanto política contrainsurgente. Paralelo a la expansión del paramilitarismo, se fue registrando el copamiento sobre estructuras de poder e instituciones públicas, en la perspectiva de dar forma a un proyecto político de alcance nacional cuyo epicentro fue la costa norte de Colombia de donde irradió al resto del país.

El copamiento fue tan elemental como brutal. El paramilitarismo impuso alcaldes, gobernadores y presidente de la república. En los dos primeros casos, eliminó a los contendientes de sus candidatos, amenazó, humilló y castigó a la población en caso de no votar por sus candidatos. Cuando los resultados fueron adversos, corrompieron a las autoridades electorales y, si esta tercera opción fallaba, eliminaban al gobernador o alcalde elegido. En el segundo de los casos, es un hecho reconocido el fraude electoral en zonas de dominio paramilitar a favor del entonces candidato Uribe Vélez.

Frente al poder legislativo (concejos municipales, asambleas departamentales, cámara de representantes y senado), en todos los casos determinaron quienes podían ser candidatos y quienes no y, en consecuencia quienes resultarían elegidos. Se denunciaron casos en que para cámara de representantes y senado a los aspirantes a tales cargos se les asignó astronómicas cifras de dinero para garantizar el éxito de los mismos y, en otros casos, se les cobró una especie de impuesto por hacer política en sus zonas de influencia. En cualquiera de los casos, los elegidos quedaron comprometidos con el paramilitarismo.

Se afirma que la Fiscalía General de la Nación, cuando estuvo bajo la orientación del político conservador Luis Camilo Osorio, se habría caracterizado por la cesación de procesos en contra del paramilitarismo, entrabar las investigaciones sobre las relaciones entre paramilitares y militares, dificultar las investigaciones sobre masacres y desplazamientos y perseguir a jueces, fiscales y funcionarios que intentaron cumplir cabalmente sus tareas. La Defensoría del Pueblo actuó medrosamente, no hizo lo suficiente por develar los hechos. La Procuraduría General de la Nación, ha estado de espaldas ante tales fenómenos. La Contraloría General de la Nación ha brillado por su ausencia en estas circunstancias, como en otras tantas. 
Ha sido la Corte Suprema de Justicia la instancia que ha intentado apersonarse del fenómeno en materia de investigación. Según tal organismo, que ha ordenado la captura de miembros del congreso colombiano por sus nexos con los paramilitares,

los resultados electorales examinados, la evidente intimidación sobre la población y demás actores políticos, la eliminación de eventuales opositores, la no admisión de candidaturas distintas a las acordadas por el grupo paramilitar y la imposibilidad del libre ejercicio de actividades proselitistas,

son situaciones reveladoras del concierto para delinquir imputados a los congresistas ${ }^{36}$ de la coalición gobernante.

El DAS, a los paramilitares, les suministró información de inteligencia sobre sindicalistas, dirigentes de izquierda y líderes populares que fueron posteriormente asesinados, borró de sus bases de datos los prontuarios de narcotraficantes y paramilitares, les legalizó el porte de armas, les otorgó facilidades para el desplazamiento consistente en vehículos blindados y seguridad personal o escoltas.

El paramilitarismo infiltró y copó varias universidades estatales, especialmente en la costa norte de Colombia. Algunos rectores no fueron elegidos democráticamente por los estamentos básicos (docentes, estudiantes, funcionarios y egresados), sino por los jefes paramilitares de la región. En esas universidades, el paramilitarismo ejecutó una especie de purga, a la usanza de lo actuado por las dictaduras. Profesores de tendencia izquierdista fueron asesinados, otros desterrados y los demás acallados. Igual suerte corrieron estudiantes y trabajadores. Las organizaciones profesorales, estudiantiles y de los trabajadores fueron extinguidas por la acción de las amenazas. Toda expresión académica resultó ser subversiva.

El nivel de copamiento sobre estructuras de poder e instituciones públicas por parte del paramilitarismo sobre el Estado colombiano alcanzó el asombroso caso de configurar un eficiente sistema tributario aplicado a las mismas instituciones y a personas naturales. Los recursos para la salud y educación en los departamentos y municipios fueron desviados a manos de los paramilitares, naturalmente con la complicidad de funcionarios, gobernantes y políticos. En municipios y gobernaciones, contratos sobre obras fueron otorgados a testaferros de los paramilitares y, en caso de no ser así, el contratista beneficiado debía pagar un porcentaje a aquellos para que se les permitiese trabajar. Los vendedores ambulantes, pequeños comerciantes, tenderos, finqueros, transportadores, expendios de estupefacientes, prostíbulos, pequeños y 
mediados empresarios también fueron obligados a pagar una especie de impuesto a los paramilitares cuyo incumplimiento acarreaba su ejecución y/o la apropiación de sus bienes.

La expansión del paramilitarismo ha dado lugar a una especie de Estado mafioso. Un Estado mafioso que, en materia de la geopolítica regional, ha profundizado su servilismo frente a Estados Unidos, genera tensión y desconfianza entre sus vecinos. En el orden interno, se sostiene en el terror y el amedrentamiento que irriga sobre la población. Esquilma al desvalido y es pródigo con el poderoso. Quienes dirigen los destinos de dicho Estado actúan como mafias del clientelismo, se hacen representar en el exterior por personajes vinculados a investigaciones penales como el embajador en Chile en el año 2005, y el cónsul en Milán en el año 2006.

El Jefe de Estado señala a sus opositores como “terroristas vestidos de civil” y a periodistas independientes como “voceros de la guerrilla”, es decir, su paradigma es similar al de los paramilitares. El paramilitarismo dio origen a una especie de clientelismo armado. Según Rut Diamint, en Colombia

\footnotetext{
... la situación ha sido descrita como un caso de ausencia de poder monopólico del Estado. A ello se agregan los efectos desestructurantes del problema de las drogas, que llevan a considerar a Colombia como un narco-Estado, en donde las autoridades de los tres poderes están financiadas por el narcotráfico y donde los narcotraficantes controlan directamente algunas agencias gubernamentales. ${ }^{37}$
}

La iglesia católica frente al fenómeno del paramilitarismo ha actuado de manera oscura y oportunista. Los pronunciamientos episcopales son acomodaticios en algunos casos, en otros, actúa abiertamente a favor del establecimiento. El Fiscalía General de la Nación, ¿se empleará a fondo para esclarecer plenamente el escándalo de la parapolítica?, no se puede perder de vista que los altos y medios cargos en los organismos de control, son el resultado de las componendas burocráticas la clase política colombiana. La fiscalía tendrá primero que depurarse, ganar credibilidad y confianza, de lo contrario, no será mucho lo que produzca en esa materia. La denominada sociedad civil está ausente en este trance por el que atraviesa Colombia, la convocatoria a marchas, paros y mítines de rechazo a la impunidad y de apoyo al esclarecimiento de la verdad, es esporádica y de poca asistencia.

\section{Reacciones frente al escándalo}


El gobierno nacional encabezado por Uribe Vélez ha reaccionado apelando a un viejo resabio consistente en defenderse, atacando a sus oponentes. No ha podido comprobar que nada tiene que ver con el paramilitarismo, apela a numerosos trucos para desviar la atención puesta sobre el fenómeno. Los senadores y representantes investigados por la fiscalía y que hacen parte de los partidos que apoyan su acción de gobierno actúan de similar modo.

Uno de esos trucos es la propuesta de un juicio al Estado, buscando con ello una especie de empate, el cual sería la antesala a una ley de punto final. A altos funcionarios del gobierno de Uribe Vélez, se les han comprobado sus nexos con paramilitares o sus familiares lo son. El hecho de haber sido electo con votos de los paramilitares y conseguidos de modo violento y fraudulento por éstos, convierte a su gobierno en ilegítimo, sostenido por medios de comunicación serviles, por Estados Unidos, por unas relaciones de poder afianzadas en el clientelismo y la corrupción y por unas fuerzas armadas convertidas en guardias pretorianas.

Las organizaciones guerrilleras y la izquierda persisten en lo que han denunciado desde hace décadas. Por su parte la izquierda "democrática” o “centroizquierda” en Colombia, compatible con el neoliberalismo, y que ahora prefiere autodemonimarse “incluyente”, frente a los hechos, asombra por sus "buenas maneras” para "no espantar la inversión extranjera, a los industriales nacionales patriotas y a las personalidades democráticas”.

El senador Gustavo Petro Urrego, del partido político de oposición, Polo Democrático Alternativo (PDA), quien ha liderado las denuncias sobre la parapolítica, reconoce que se ha interesado en el tema a raíz de la información de primera mano que, sobre el particular, le han ofrecido ex paramilitares ahora bajo protección en el exterior, especialmente en Canadá, militares que se negaron a transar con los paramilitares y víctimas de éstos y por el interés en que se conozca “toda la verdad”, se fortalezcan las instituciones y se repare a las víctimas.

El PDA, instó al presidente para que ofreciera explicaciones sobre el escándalo de la parapolítica, según tal partido político, los congresistas presos, sindicados de tener nexos con paramilitares, militan en organizaciones que han respaldado al mandatario.

El Presidente Uribe no ha dado ninguna explicación política de por qué tantos amigos suyos quienes lo respaldaron con sus votos, lo acompañaron en sus giras electorales y le financiaron sus campañas presidenciales, al igual que recibieron el respaldo del Presidente desde el gobierno - resultaron vinculados con las organizaciones paramilitares, 
se pregunta dicho partido político. ${ }^{38}$

Las fuerzas armadas, pese a los llamados que el Ministro de Defensa Juan Manuel Santos Calderón les ha hecho para que confiesen si tuvieron o tienen vínculos con los paramilitares, ninguno de sus miembros ha dado el paso al frente para actuar en consecuencia. Es de suponer que miembros de las mismas tienen información privilegiada sobre relaciones con los paramilitares y de las del resto de la sociedad con aquellos. Cuando miembros del paramilitarismo han amenazado con decir la verdad sobre los vínculos con militares, empresarios y políticos, son asesinados y sus familias intimidadas. De modo aislado, oficiales en uso de buen retiro, como es el caso del coronel Carlos Alfonso Velásquez, consideran que ha sido un error estratégico la alianza entre militares y paramilitares, la cual se debe, según el mismo, a que las elites colombianas y las fuerzas armadas no poseen un pensamiento estratégico frente a la guerrilla; el hacer prevalecer una estrategia equivocada consistente en fijar, como principal indicador de gestión, el número de bajas causadas a la guerrilla; así como a problemas éticos en la formación de los militares.

Los medios de comunicación han hecho del escándalo un espectáculo. Tienen una enorme responsabilidad ética, moral, social y política respecto al esclarecimiento de estos hechos de la historia colombiana, sin embargo, parece ser que pesan más los intereses de grupos y de elites que los de la nación a la cual informan. La información que poseen, la manipulan y no la difunden completamente. Se imponen así mismos una especie de censura.

Estados Unidos por su parte, mientras sus intereses no se pongan en riesgo, nada le importa si en Colombia existe un Estado mafioso, tampoco las dimensiones éticas, morales e ideológicas de los vínculos de la clase política y los militares con los paramilitares y por ende con los narcotraficantes. Pues al fin y al cabo también se trata de un Estado que también incurre en prácticas terroristas en ámbito internacional. ${ }^{39}$ En materia estructural, le interesa ahondar las relaciones de dependencia, en lo coyuntural, poner el marcha el Tratado de Libre Comercio y exacerbar más conflicto colombiano como parte de la estrategia bélica para la región andina.

El proceso de paz adelantado por el gobierno nacional de Uribe Vélez con las organizaciones paramilitares pareciese no corresponder a un proceso de paz ya que ni siquiera las acciones de estos han cesado, sino más bien, a una estrategia política de largo aliento en Colombia, consistente en legalizar las fortunas adquiridas por 
paramilitares, narcotraficantes y altos funcionarios estatales; en justificar y posicionar el proyecto político de la extrema derecha; en simular juicios ante la justicia colombiana para evadir la acción de la justicia estadounidense.

En el marco de la ley que regula dicho proceso de paz se presenta una curiosa situación. Presuntamente los paramilitares están obligados a confesar “todos” sus crímenes y, en caso de no hacerlo, confesar a medias u omitir algunos, perderán los beneficios. Sin embargo, los funcionarios del sistema judicial colombiano, no disponen de todo el prontuario para contrastar si efectivamente quien confiesa lo está haciendo a plenitud. La información de que dispone la justicia colombiana de cada paramilitar, es fragmentaria, superficial e incompleta. Se sabe que muchos de ellos, ni siquiera estaban siendo requeridos por la justicia y por eso quedan en libertad. Queda en consecuencia, a voluntad del paramilitar, si confiesa todo, una parte o acomoda a su amaño e interés los hechos con calculado propósito. El paramilitar decide qué confiesa y qué no, cómo lo hace, cómo matiza, relativiza, niega o justifica. El rol de quien actúa como juez parece ser pasivo, en el sentido de esperar que su interlocutor proceda narrar hechos según le convenga.

Respecto a la confesión preliminar hecha en enero de 2007 por uno de los máximos líderes de los paramilitares, el señor Salvatore Mancuso Gómez, de modo reiterado, afirma que las acciones de los paramilitares, siempre y en todo caso, contaron con el apoyo del conjunto de las fuerzas armadas y de la policía nacional y, al momento de mencionar nombres concretos, relaciona a oficiales muertos. Reitera lo ya expuesto por Carlos Castaño Gil, en el sentido de que hubo un llamado "Comité de los ocho", compuesto por personalidades de "reconocida solvencia moral" y de "reconocida trayectoria política en el país”, encargado de señalar a quien se debía eliminar. Las masacres en las que confiesa haber participado, las justifica como "exitosos partes de guerra contra del enemigo” y las ejecuciones individuales de alcaldes, concejales y demás, las justifica como “acciones en contra de la corrupción”. De las acciones más escabrosas, inculpa al extinto Castaño Gil. La confesión, en todo y sus partes, denota un esfuerzo por asignarle a sus acciones una dimensión política.

La mencionada confesión, en otros países, hubiese provocado la irrupción de masivas marchas de la ciudadanía reclamando claridad en los hechos confesados y castigo a los culpables, así como la renuncia de altos oficiales, ministros y del propio presidente. Pero no, en la lógica del cinismo canicular que en Colombia parece haberse convertido en la norma generalizada por la cual se miden gobernantes y gobernados, 
usualmente se espera que un escándalo mayor cubra con su sombra a este o que un episodio banal desvíe la atención de los colombianos. Pese a todas las acusaciones y evidencias en contra, las fuerzas armadas, se aferran al argumento, según el cual los nexos entre militares y paramilitares son individuales, aislados y no institucionales.

Como parte de este endogámico proceso de paz, se creó una comisión para la reparación de las víctimas, presidida por el sociólogo Eduardo Pizarro Leóngomez y parte de sus declaraciones auguran una burla a las víctimas. Tal funcionario ha manifestado, en primer lugar, que los recursos destinados a la reparación de las víctimas, son insuficientes. En segunda instancia y, concomitante con lo anterior, que parte de la reparación tendrá que ser simbólica. En tercer lugar, escamotea el espíritu de la ley y se pone a favor de los victimarios y del gobierno nacional que en el fondo son un mismo actor del conflicto, al impulsar la tesis, según la cual, la reparación también debe ir dirigida hacia las víctimas de las acciones de las guerrillas y remontarse hasta la década de los años sesenta del siglo XX.

\section{Reflexiones finales}

Durante la administración de Uribe Vélez, resaltan tres tendencias de la situación de Derechos Humanos: aumento de las ejecuciones extrajudiciales atribuibles a la fuerza pública por medio de los falsos positivos, el incremento de las detenciones arbitrarias y la paramilitarización de la sociedad y las instituciones. Esta última tendencia, en el plano militar se expresa en el hecho de que paramilitares se institucionalizaron a través de empresas e instituciones, en el ámbito económico controlan actividades ilegales y además participan de proyectos agroindustriales con el auspicio del gobierno ${ }^{40} \mathrm{y}$, en materia política, está el escándalo de la parapolítica. El gobierno nacional, en tanto que resultado y expresión del paramilitarismo, es juez y parte en ese proceso de paz por medio del cual se institucionaliza el paramilitarismo, donde las víctimas o familiares de las mismas adolecen de fuertes organizaciones locales, regionales y nacionales. Sus luchas son individuales, insulares y desarticuladas de proyecto político alguno, aparte de que sus voceros son asesinados.

El paramilitarismo en Colombia, transformó a este país. Borró de un plumazo los múltiples intentos de reforma agraria. Incidió en la configuración de nuevas características demográficas y con ellas la agudización de problemas ligados a las necesidades básicas insatisfechas, fenómeno determinante en la pauperización de la 
mayoría de la población. Estimuló la degradación de la guerra. En el ámbito social, familiar e individual afianzó valores como el lucro fácil, el consumismo, la intolerancia, la agresividad, la justificación de cualquier medio para alcanzar un fin, el despilfarro y la ostentación. Coadyuvó en la polarización de la sociedad. Contribuyó a la consolidación de una ética política basada en el señalamiento, la estigmatización, la exclusión, la corrupción, el clientelismo armado y la violencia.

El fenómeno del paramilitarismo y el escándalo provocado, deben ser vistos desde una perspectiva estructural, encuadrada en la geopolítica y la razón de Estado que Estados Unidos adoptó para este país en virtud de sus seculares conflictos, también articulada a la evolución de las distintas violencias y éstas a la dinámica de un capitalismo periférico y dependiente. Soslayar los análisis de estas mínimas coordenadas, sitúa a quien lo intente, en la perspectiva de que la hoja no deja ver la rama, la rama no deja ver el árbol y el árbol no deja ver el bosque, pues los paramilitares, entre otras cosas, son parte de la política contrainsurgente impuesta por Estados Unidos.

A las antiguas tareas antisubversivas de las fuerzas armadas colombianas, Estados Unidos le sumó otras, como la represión al cultivo, tráfico y consumo de estupefacientes; la custodia de la infraestructura minera, energética, petrolera y de comunicaciones donde hay capitales estadounidenses invertidos; el servicio de seguridad para el personal uniformado y civil de ese país, que cumplen funciones militares y políticas en Colombia; la de ser consumidores netos y compulsivos de la industria militar estadounidense y el ser el principal sostén de regímenes políticos civiles corruptos e ilegítimos. No importó a Estados Unidos si para el cumplimiento de esas tareas las fuerzas armadas colombianas, auspiciaran organizaciones paramilitares o se aliaran con las ya existentes.

Mancuso Gómez expresó en su confesión que cadáveres de civiles o de los mismos paramilitares masacrados por su organización fueron entregados al ejército nacional, institución que los presentaba como guerrilleros muertos en combate. Si ello fuere así, su incompetencia para derrotar a las organizaciones subversivas y su mediocridad en los resultados ha empujado al estamento castrense a incurrir en este tipo de prácticas en el afán por mostrar resultados; pese a que desde antes de los años ochenta se habían identificado situaciones que incidían en el bajo desempeño de los militares colombianos en su lucha contra la subversión y señalado los errores más frecuentes de la misma, continúan incurriendo en las mismas fallas, cuestión que 
contribuye a explicar su descomposición moral; la Doctrina de la Seguridad Nacional y la razón de Estado derivada de la misma, condenó a las fuerzas armadas de Colombia a combatir guerras sin brillo, desprovistas de honor, sin hidalguía, sin pundonor ni hombría; el paramilitarismo las envileció; la razón de Estado, del Estado colombiano y la de Estados Unidos convirtieron a las fuerzas armadas, de pretendidas características nacionales, en una institución al servicio de una ideología contrainsurgente.

¿De qué manera benefició o beneficia el paramilitarismo a Estados Unidos? Frena, retrocede o aniquila distintas expresiones de la izquierda; contribuye al éxito electoral de candidatos pro-estadounidenses; intimida y acribilla el pensamiento crítico; asesina a sindicalistas de las multinacionales estadounidenses; contribuye a la imposición del neoliberalismo; "libera” zonas estratégicas de la "amenaza subversiva”; estimula el armamentismo; profundiza la dependencia de Colombia; promueve el pensamiento neoliberal afín a la globalización; sirve de laboratorio de prueba de estrategias antisubversivas; en materia geopolítica incide en la correlación de fuerzas en el área andina, a favor de Estados Unidos; le otorga mayores argumentos para persistir en la lucha contra las drogas; mantiene latentes conflictos, a partir de los cuales, Estados Unidos cualifica y cuantifica su intromisión en los asuntos internos de Colombia. Este tipo de beneficios concuerda con los intereses de Estados Unidos en materia de seguridad y, por ende, con su razón de Estado, en la perspectiva de ampliar y consolidar su poder.

El paramilitarismo en Colombia no se puede explicar solamente como una reacción ante los atropellos de la delincuencia, los abusos y el crecimiento de las organizaciones guerrilleras. Hace parte de la razón de Estado puesta en práctica por las mafias que han orientado los destinos de dicho país y que para afianzarse en el poder, recurren a prácticas viles.

VELÁSQUEZ RIVERA, Edgar de Jesús. History of the paramilitarismo in Colombia. História, São Paulo, v. 26, n. 1, p 134-153, 2007.

Abstract: In Colombia, since the eighties of the XXth century, the paramilitarism has been taking force as a strategy against insurgence, a kind of politics which has not been yet recognized by part of different governments, being expressed State terrorism. It caused the emergence of such a phenomenon named anticommunist ideology, professed by most Armed Forces members, political culture that comes from violence, corruption and clientelism as well as from drug dealing, and external influences, mainly from France and the United States. Paramilitarism has invaded all the different structures of the state power aiming 
at forming itself as a political, military, social and economic project at national level. According to its mentors, paramilitary groups have resulted from a reaction to the guerrilla movements excesses. Paramilitarism has been choosing, as a fight method, selective massacres, murders and displacements of civil population suspicious of supporting and collaborating with guerrilla groups. President Álvaro Uribe Vélez is accused by his political opponents of sustaining and institutionalizing paramilitary groups.

Keywords: paramilitary, power, violence, government.

Artigo recebido em 03/2007. Aprovado em 06/2007

\section{NOTAS}

* Doctor en Historia, Pontificia Universidad Católica de Chile. Profesor, Departamento de Historia, Universidad del Cauca.Dirección: Urbanización La Aldea, Agrupación 10 n 10-01, Popayán, Cauca, Colombia. Teléfono +57 (2) 8247777. Correos electrónicos: velasquezrivera@unicauca.edu.co velasquezrivera@gmail.com

${ }^{1}$ ROBIN, M-M. Escuadrones de la muerte. La escuela francesa. Buenos Aires: Sudamericana, 2005. p.33.

${ }^{2}$ ROBIN, M-M. Op. cit., p.121.

3 TRINQUIER, R. La guerra moderna y la guerra contra las guerrillas. Barcelona: Herder, 1965. p.53.

${ }^{4}$ TRINQUIER, R. Op. cit., p.55-61.

${ }^{5}$ TRINQUIER, R. Op. cit., p.68-69.

${ }^{6}$ TRINQUIER, R. Op. cit., p.173-181.

${ }^{7}$ ROBIN, M-M. Op. cit., p.133.

${ }^{8}$ ROBIN, M-M. Op. cit., p.223

${ }^{9}$ ROBIN, M-M. Op. cit., p.281.

${ }^{10}$ ROBIN, M-M. Op. cit., p.239

${ }^{11}$ GILL, L. Escuela de las Américas. Entrenamiento militar, violencia política e impunidad en las Américas. Santiago: Lom, 2005. p.44.

${ }^{12}$ COMBLIN, J. El poder militar en América Latina. Salamanca: Sígueme, 1978. p.58.

${ }^{13}$ GILL, L. Op. cit., p.44.

${ }^{14}$ GARCÍA-PEÑA JARAMILLO, D. El paramilitarismo. El Espectador, Bogotá, p.54-55, marzo 22 de 2007.

${ }^{15}$ CATATUMBO, P. La doctrina de la seguridad nacional: el principal obstáculo para la paz, en Revista Javeriana, n.590. Bogotá, v.118, p.308-312, noviembre-diciembre de 1992.

16 Ibid.

${ }^{17}$ LERCHE, CH O. SAID, A. A. La guerra en el mundo moderno. Revista de las fuerzas armadas, n.83, Bogotá, v.28, p.202-206, mayo-agosto de 1976.

${ }^{18}$ PIZARRO LEONGÓMEZ, E. La guerrilla en Colombia. Entre la guerra y la paz. Puntos de vista sobre la crisis de los años 80. Controversia, n.141, Bogotá: CINEP, p.144- 147, 1987.

19 VÁSQUEZ CARRIZOSA, A. Historia crítica del Frente Nacional. Bogotá: Foro Nacional por Colombia, 1992. p.228.

${ }^{20}$ MEDINA GALLEGO, C. TÉLLEZ ARDILA, M. La violencia parainstitucional, paramilitar y parapolicial en Colombia. Bogotá: Rodríguez Quito, 1994. p.64.

${ }^{21}$ VARGAS VELÁSQUEZ, A. Las fuerzas armadas en el conflicto colombiano. Antecedentes y perspectivas.Bogotá: Intermedio, 2002. p.281.

22 Ibid.

${ }^{23}$ MEDINA GALLEGO, C. TÉLLEZ ARDILA, M. Op. cit., p.64.

${ }^{24}$ GARCÍA-PEÑA JARAMILLO, D. Op. cit., p.54.

${ }^{25}$ GARCÍA-PEÑA JARAMILLO, D. Op. cit., p.55. 
${ }^{26}$ ZAMORA, G L. El Magdalena Medio: los moradores de la represión. Bogotá: CINEP, 1983. p.43.

${ }^{27}$ CEPEDA CASTRO, I. Respaldo institucional. El Espectador. Bogotá, p.19 A, semana del 21 al 27 de enero de 2007.

${ }^{28}$ Ibid.

${ }^{29}$ GILL, L. Op. cit., p.238.

${ }^{30}$ Revista Semana, n.1291, Bogotá, p.12-16, enero 29-febrero 5, 2007.

${ }^{31}$ Tras los pasos perdidos de la guerra sucia. Paramilitarismo y operaciones encubiertas en Colombia, Bruselas, 1995. Paramilitarismo en Colombia. Órdenes del alto mando. Revista Alternativa, Bogotá, p.314, octubre de 1996.

${ }^{32}$ AMAT, Y. El reportaje de Yamid, El Tiempo, Bogotá, p.1-24, 22 de octubre de 2006.

${ }^{33}$ El Espectador. Bogotá, p. 2 A, semana del 18 al 24 de febrero de 2007.

${ }^{34}$ GARCÍA SEGURA, H. La Colombia del acuerdo "para”. El Espectador, Bogotá, p.3 A, semana del 21 al 27 de enero de 2007.

${ }^{35}$ PARDO RUEDA, R. Las ventajas de la sudadera. El Tiempo, Bogotá, p.1-17, 22 de febrero de 2007.

${ }^{36}$ El Espectador, Bogotá, p.2 A, semana del 18 al 24 de febrero de 2007.

${ }^{37}$ DIAMINT, R. Cuestiones militares en América Latina. In: DOMÍNGUEZ, J. I. SHIFTER, M. (editores). Construcción de gobernabilidad democrática en América Latina. Bogotá: Fondo de Cultura Económica, 2005. p.54-62.

${ }^{38}$ El Tiempo, Bogotá, p.1-4, 22 de febrero de 2007.

${ }^{39}$ La Nación, Santiago, p.7-8, 17 de noviembre de 2005.

4010 de diciembre. Día internacional de los Derechos Humanos, separata, Coordinación ColombiaEuropa-Estados Unidos, Bogotá, p.1-9, 10 de diciembre de 2006. 